
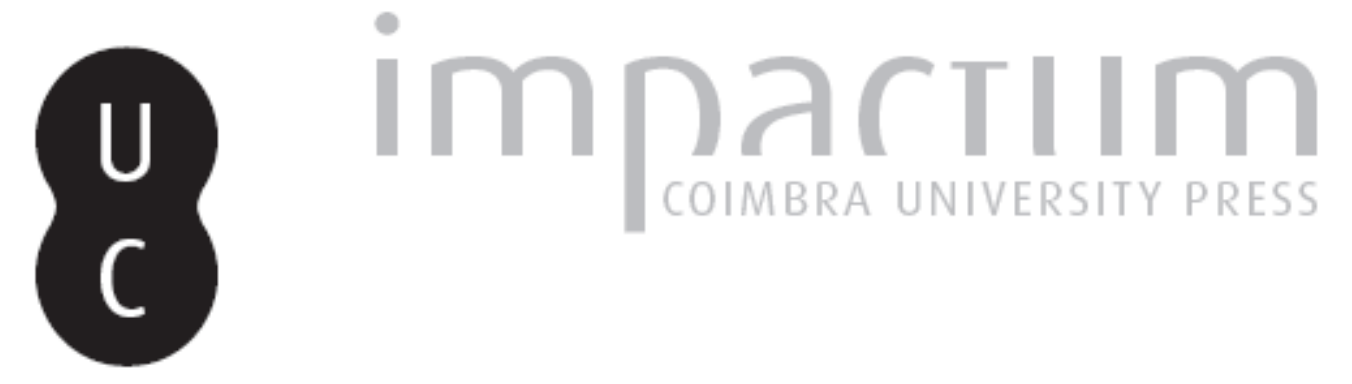

\title{
Condições e dificuldades de constituição da opinião pública
}

\author{
Autor(es): $\quad$ Rodrigues, Adriano Duarte
}

Publicado por: Imprensa da Universidade de Coimbra

URL persistente:

URl:http://hdl.handle.net/10316.2/41225

DOI:

DOI:https://doi.org/10.14195/2183-6019_3_10

Accessed : $\quad$ 26-Apr-2023 08:12:56

A navegação consulta e descarregamento dos títulos inseridos nas Bibliotecas Digitais UC Digitalis, UC Pombalina e UC Impactum, pressupõem a aceitação plena e sem reservas dos Termos e Condições de Uso destas Bibliotecas Digitais, disponíveis em https://digitalis.uc.pt/pt-pt/termos.

Conforme exposto nos referidos Termos e Condições de Uso, o descarregamento de títulos de acesso restrito requer uma licença válida de autorização devendo o utilizador aceder ao(s) documento(s) a partir de um endereço de IP da instituição detentora da supramencionada licença.

Ao utilizador é apenas permitido o descarregamento para uso pessoal, pelo que o emprego do(s) título(s) descarregado(s) para outro fim, designadamente comercial, carece de autorização do respetivo autor ou editor da obra.

Na medida em que todas as obras da UC Digitalis se encontram protegidas pelo Código do Direito de Autor e Direitos Conexos e demais legislação aplicável, toda a cópia, parcial ou total, deste documento, nos casos em que é legalmente admitida, deverá conter ou fazer-se acompanhar por este aviso.

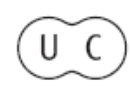


revista de comunicação,

jornalismo e espaço público

3

Periodicidade

Semestral

Imprensa da Universidade de Coimbra

Coimbra University Press

\section{mediapolis}

tema

o ensino do jornalismo

no século XXI

$\underline{ }$ 


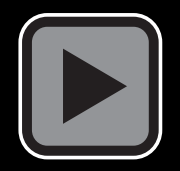




\section{Condições e dificuldades de constituição da opinião pública}

Conditions and difficulties of building the public opinion

Resumo:

Este texto pretende mostrar que a opinião pública é, por um lado, uma noção contraditória e, por outro lado, de difícil constituição. A sua natureza contraditória tem a ver com o facto de, para o público que se reconhece nos seus conteúdos proposicionais, a opinião pública não ser uma opinião mas uma certeza e de, para o público não se reconhece nesses conteúdos, a opinião pública ser uma opinião mas não ser pública. Tenta depois mostrar que, de qualquer modo, a constituição da opinião pública é difícil, em virtude da natureza efémera e fragmentária da experiência moderna em que ela emerge.

Palavras Chave: Experiência, jornalismo, opinião pública, reconhecimento, responsabilidade, solidariedade.
Abstract:

This paper aims to show that public opinion is a contradictory notion as well as an entity that is difficult to be enacted. It has a contradictory nature because the public who recognizes itself in its propositional contents does not take it as an opinion but as a fact and the public who doesn't recognize itself in it, public opinion is not public. The article then proceeds to show the difficulties in enacting public opinion given the ephemeral and fragmental nature of modern experience that emerges from it.

Keywords: Experience, journalism, public opinion, recognition, responsibility, solidarity. 
Os estudiosos da comunicação estão muitas vezes tão envolvidos com questões mediáticas que acabam por se convencer de que são os media, em geral, e os jornalistas, em particular, que produzem a opinião pública, esquecendo-se de que são as pessoas, e não os media, que a constituem com as interações conversacionais em que se envolvem no quadro da vida quotidiana. Com este texto pretendo simplesmente recordar esta verdade elementar e, deste modo, chamar a atenção para a importância de complementar o estudo dos discursos produzidos em ambientes mediáticos com os estudos dos discursos produzidos pelas pessoas nos ambientes de interações conversacionais em que se envolvem constantemente no quadro da vida quotidiana.

Antes de abordar propriamente a relação do jornalismo com a opinião pública, gostaria de começar por esclarecer o sentido da expressão opinião pública, mostrando que se trata de uma expressão logicamente absurda. Para o provar basta observar que aquilo a que damos o nome de opinião se expressa por um enunciado que possui um conteúdo proposicional não categórico e, por conseguinte, discutível. Como tal, uma opinião pública não pode ser validada por uma razão universal e, por isso, só tem valor em função da sua aceitação por parte das pessoas que se reconhecem como membros de um público. O conteúdo da proposição que faz parte de uma opinião pública, se fosse validada racionalmente, possuiria um valor categórico universal e não seria uma opinião, não seria uma proposição dóxica, mas uma proposição epistémica com o valor de certeza. E, no entanto, aquilo a que se dá o nome de opinião pública só é válida para um público particular que a aceita, não como opinião, mas como certeza. Como vemos, o conteúdo proposicional de um enunciado só é uma opinião para os que não pertencem ao público que não a aceita como opinião e só é pública para os que não a aceitam como opinião, mas como certeza.

Aquilo a que se dá o nome de opinião pública formula um juízo categórico de valor que pode incidir, quer sobre a verdade ou a falsidade, quer sobre a bondade ou maldade, quer sobre a beleza ou a fealdade de um determinado estado de coisas. Por estado de coisas entendemos o referente de um enunciado que adquire o valor de realidade pelo facto de ter sido enunciado ${ }^{1}$. Pode ser um objeto, como, por exemplo, uma mesa, uma casa, uma montanha ou uma pessoa; pode ser um acontecimento, como, por exemplo, um terramoto, uma guerra; pode ser o estado de um objeto, como, por exemplo, o estado líquido, sólido ou gasoso; pode ser o estado de uma pessoa, como, por exemplo, um pai, uma mãe, um filho, uma filha ou um operário; pode enfim ser uma entidade abstrata, como a bondade, a democracia ou a justiça.

Damos o nome de ontológicos aos juízos categóricos de valor que incidem sobre a verdade ou a falsidade de um determinado estado de coisas. Damos o nome de éticos aos juízos categóricos de valor que incidem sobre a bondade ou a maldade de um determinado estado de coisas. Damos o nome de estéticos aos juízos de valor que incidem sobre a beleza ou a fealdade de um determinado estado de coisas. Assim, por exemplo, o

1 Abordei as questões da referência em Rodrigues 2005, p. 63 e ss. 
enunciado "o ser humano existe desde a conceção" é um juízo categórico ontológico, que asserta a verdade acerca da existência de um determinado estado de coisas, mas o enunciado "o aborto é uma prática condenável” é um juízo ético. Estes exemplos são interessantes porque mostram que existe habitualmente nos enunciados daquilo a que se costuma dar o nome de opinião pública uma confusão entre os valores ontológicos e os valores éticos, confusão característica da modalidade tradicional da experiência, no quadro da qual não existe autonomia da dimensão ontológica em relação às dimensões ética e estética da experiência. É esta característica que, a meu ver, levava Gabriel Tarde a considerar a opinião pública como etapa de constituição da tradição (Tarde, 2006, p. 57 e ss.).

É suficientemente conhecido o processo histórico de constituição da esfera pública no mundo ocidental estudado por Hannah Arendt (Arendt, 2001) e por Jürgen Habermas (Habermas, 2012). Por considerar suficientemente conhecido este processo, abstenho-me nesta comunicação de o abordar, mas é a partir de uma reflexão acerca desse quadro complexo de configurações que a constituição da esfera pública foi apresentando ao longo da história ocidental que gostaria agora de enunciar as condições de constituição do público e abordar algumas das atuais dificuldades da sua formação. Estas dificuldades resultam das transformações ocorridas nas nossas sociedades a partir da segunda metade do século XIX, com a industrialização da imprensa e a formação dos seus agentes privilegiados, dos jornalistas.

\section{As condições de constituição do público}

Proponho agrupar as condições para a constituição do público em torno da lógica que regula dois processos sociais distintos: a lógica do reconhecimento e a lógica da responsabilidade. Uma breve definição desta lógica. Começarei por sublinhar que, com estes termos, não designo princípios voluntaristas, mas processos sociais que decorrem do entendimento antropológico da experiência como processo simbólico reflexivo de interação social, no sentido que lhe deu em particular George Herbert Mead (Mead, 1992).

Neste sentido, por reconhecimento entendo o processo que leva as pessoas a se reconhecerem a si próprias, a reconhecerem os outros e a serem por eles reconhecidas como membros de uma comunidade. São membros de uma comunidade todos quantos possuem interiorizadas e partilham entre si um conjunto de marcas simbólicas e que manifestam essa interiorização e partilha nos comportamentos que adotam e nas ações que empreendem nas suas interações sociais (Marcos \& Monteiro, 2008). O reconhecimento é, por conseguinte, o processo que decorre do facto de os indivíduos 1 . escolherem a maneira de se comportarem e de agirem de acordo com aquilo que sabem que os outros esperam que eles escolham e façam; 2 . de saberem como articular ou agenciar o seu comportamento com os comportamentos e as ações que os outros adotam; e 3. de saberem que os outros esperam que se comportem ou ajam como eles se comportariam ou agiriam nas mesmas circunstâncias ou em circunstâncias semelhantes. Podemos, por conseguinte, identificar até certo ponto aquilo 
a que George Mead dava o nome de “outro generalizado" com o princípio constitutivo do público (Mead, 1992).

Por seu lado, a responsabilidade é a competência própria das pessoas que formam um público e que consiste na capacidade, por um lado, para responder a alguém que pergunte a razão que as leva a adotar determinado comportamento ou a empreender determinada ação e, por outro lado, para exigir que as pessoas que fazem parte de um público respondam à pergunta pela razão que as leva a adotar determinado comportamento ou a empreender determinada ação.

\section{As dificuldades de \\ constituição do público}

$\mathrm{O}$ que eu gostaria agora de mostrar é o facto de estes dois processos de constituição do público, o do reconhecimento e o da responsabilidade, serem hoje particularmente difíceis e de esta dificuldade resultar da natureza da solidariedade e da experiência técnica do nosso tempo.

A natureza do processo de solidariedade é, no quadro da experiência moderna, a primeira dificuldade com que a constituição da esfera pública se confronta, em virtude de este processo ter tornado particularmente ambivalente o reconhecimento e de, por isso, a sua exigência para a constituição da esfera pública se ter tornado problemática.

No quadro da experiência moderna, contraposta ao quadro do que podemos observar no quadro da experiência tradicional, as relações de solidariedade, por um lado, ultrapassam o âmbito do território de pertença e, por outro lado, deixam de abranger o conjunto de todos os domínios e de todas as dimensões da experiência. Deixamos de depender da solidariedade dos que partilham connosco o mesmo território, à medida que as relações de solidariedade, por um lado, passam a ser independentes da pertença a comunidades concretas de pessoas que se reconhecem como membros de uma mesma comunidade, das pessoas que identificam as mesmas marcas simbólicas, que possuem uma mesma história comum e se veem mutuamente envelhecer, e, por outro lado, se tornaram efémeras e por isso volúveis. Podemos, por exemplo, estabelecer relações de solidariedade com a fome de crianças que vivem em países longínquos e não ver as crianças pobres que vivem no mesmo prédio ou no mesmo território em que habitamos.

As pessoas estabelecem hoje relações de solidariedade com uma grande diversidade de públicos, consoante os domínios da experiência. A esta multiplicidade de relações de solidariedade dava Emile Durkheim o nome de solidariedade orgânica (Durkheim, 1991). Cada um de nós faz hoje parte de públicos muito diversificados, estabelecendo com cada uma destas modalidades distintas de públicos uma multiplicidade de relações de solidariedade, decorrentes de modalidades diferenciadas de reconhecimento. Posso ser solidário com as pessoas da minha família, com os meus colegas de trabalho, com as pessoas que pertencem a um partido político, com os frequentadores de um clube desportivo, com os membros de uma associação filantrópica, com os cidadãos do meu país. Cada uma destas diferentes relações de solidariedade forma públicos distintos, porque em cada uma delas, eu me reconheço diferente, adoto comportamentos adequados diferentes, sou reconhecido como 
parceiro de interesses e de visões do mundo próprios que são comuns aos seus membros, possuo um conjunto de marcas simbólicas próprias que partilho com os outros membros de cada um dos públicos de pertença / ou de referência.

A consumação do processo de constituição da natureza orgânica da solidariedade torna problemática a exigência do reconhecimento como fator de constituição do público. Antes de mais porque o reconhecimento se tornou um valor relativo e volúvel. Posso me reconhecer como um membro do público académico, ser reconhecido pelos meus colegas e reconhecer os que partilham comigo a mesma profissão e não me reconhecer nem ser reconhecido no mundo político, no mundo económico ou no mundo desportivo. A minha opinião pode ser escutada e respeitada por um dos públicos em que me envolvo e ser completamente ignorada por outros. Posso reconhecer a opinião das pessoas que frequentam o ginásio que eu frequento, mas ignorar a opinião das pessoas que habitam o meu prédio ou que fazem as compras no mesmo supermercado onde eu faço as minhas compras ou que tomam habitualmente o almoço no restaurante que eu frequento.

Mas a exigência do reconhecimento é particularmente difícil porque é regulada por dois princípios contraditórios, a que darei, seguindo aliás a sugestão de Nancy Frazer (2007), o nome de princípio da igualdade e de princípio da diferença. A leitura igualitária do reconhecimento é sobretudo a que fazem os autores liberais de direita, para quem o reconhecimento deve assegurar uma distribuição justa dos recursos disponíveis a todas as pessoas. Por seu lado, a leitura diferenciadora do reconhecimento é sobretudo a dos autores de esquerda, para quem o reconhecimento é o respeito das diferenças que definem a identidade de cada uma das pessoas e de cada uma das comunidades humanas, respeitando inclusivamente a diferença dos que pretendem prescindir dos recursos de que outros não abdicam. Se por recursos entendermos apenas os bens materiais, talvez o problema, não seja particularmente difícil de resolver, mas se alargarmos a noção de recursos aos bens jurídicos, como os que têm que ver com, por exemplo, as diferenças de género, de orientação sexual, de ostentação de marcas simbólicas próprias de uma comunidade, as dificuldades avolumam-se e acabam por ter a ver com a gestão do princípio da tolerância, princípio que é de natureza circular e, por isso, paradoxal.

A natureza fragmentária da experiência moderna decorrente da especialização dos seus diferentes domínios agudiza as dificuldades de definição do bem comum e do interesse geral, entendidos como resultado daquilo que as pessoas particulares ou associadas nos diferentes campos entendem ser o bem comum e o interesse geral. A partir do momento em que o público se torna a instância legítima, torna-se difícil satisfazer os interesses de cada campo e, deste modo, definir aquilo que é o bem comum. Esta dificuldade aumenta se tivermos em conta que muitas das decisões a tomar no presente têm consequências no futuro e as consequências futuras das decisões tomadas no presente são difíceis de apreciar devidamente, pelo facto de envolverem fatores imponderáveis e, mesmo que fosse possível defini-los com clareza, é muito difícil mobilizar os interesses atuais do público de modo a enfrentá-las racionalmente. Sabemos como é difícil levar 
as pessoas a decidirem prescindir da utilização de recursos escassos em vias de extinção, tendo em conta o interesse das gerações vindouras.

Gostaria agora de abordar a outra dificuldade que mencionei, a dificuldade com que a esfera pública hoje se confronta decorrente da natureza sistémica da tecnicidade das sociedades contemporâneas.

A experiência técnica contemporânea tornou-se predominantemente sistémica, em virtude do devir dispositivo dos objetos técnicos inventados no quadro do modelo cibernético da tecnicidade. Estas transformações têm como consequência efeitos notáveis, tanto na experiência individual, como na experiência coletiva. Uma das manifestações mais óbvias é o facto de as pessoas terem deixado de dominar e de compreender a natureza dos objetos técnicos que utilizam e de, por isso, não poderem intervir na elaboração dos dispositivos que utilizam na sua interação com o mundo, não só com o mundo natural e com o mundo intersubjetivo, mas também com o seu próprio mundo subjetivo, tornando-se o funcionamento destes dispositivos tanto mais naturalizado quanto menos compreendido.
A consequência da natureza sistémica dos dispositivos técnicos é paradoxal, visto que as pessoas têm um acesso cada vez mais fácil e quotidiano aos dispositivos, à medida que se veem desapropriadas da possibilidade de compreender a sua estrutura e de poderem intervir na sua elaboração. O resultado destas transformações é a cada vez maior dependência de especialistas e de peritos, quando se confrontam com dificuldades de manuseamento e quando têm de tomar decisões acerca da escolha dos objetos técnicos para realizarem as suas tarefas.

A tecnicidade dos seres humanos converte-se, assim, numa tecnicidade de uso. A este propósito, faço minha a exigência de uma formação técnica dos cidadãos que os habilite a compreender a natureza da tecnicidade como condição de formação plena para a cidadania, exigência que já Gilbert Simondon formulava, no final dos anos 50 do século passado (Simondon, 1989, p. 106-112).

\section{Conclusão}

Creio que o percurso que segui ao longo deste texto aponta para uma visão da esfera pública, não como uma realidade que possamos encontrar ou de que possamos definir os contornos, mas como um processo em que os seres humanos se envolvem em permanência tendo em vista encontrar a maneira de viverem em comum. Dito de outro modo: a esfera pública não existe nem resulta do funcionamento dos media, mas projeta-se como um ideal nunca completamente alcançado dos processos de interação entre as pessoas no quadro das interações que estabelecem entre elas no quadro da sua vida quotidiana, no quadro em que os processos de solidariedade e de responsabilidade se desenrolam. Em cada sociedade e em cada época, este ideal apresenta configurações específicas que resultam da maneira como as pessoas interagem entre si tendo em vista o ajustamento dos seus comportamentos e a maneira como se confrontam com as consequências das suas ações. É por isso que, tal como já Tarde sublinhava em 1901, a conversação é a atividade fundamental de constituição do público ou, para falarmos como John Dewey (1954), da comunidade. É importante lembrar esta evidência sobretudo num colóquio de 
estudiosos da comunicação, porque há uma tendência a associarmos a esfera pública ao funcionamento dos media e a esquecermos que a interação entre as pessoas está sempre a montante e a jusante dos media. Tal como no passado, as pessoas estão constantemente envolvidas em processos de interação regulados pela lógica da sociabilidade. É uma lógica paradoxal, dado que se, por um lado, depende dos comportamentos que as pessoas adotam por ocasião das interações em que se envolvem, por outro lado, ajusta-se em permanência aos princípios que as regulam e que são constituídos por esses comportamentos.

As exigências deste processo são reguladas por princípios ambivalentes e formam princípios que se situam a montante das regras e das normas que regulam os comportamentos coletivos ${ }^{2}$.

2 Faço aqui a distinção entre princípios de natureza distinta, a que dou o nome de regras, de normas e de constrangimentos. As regras são princípios que se aplicam para executar comportamentos que elas constituem ou fazem existir; as normas são princípios a que se obedece para adotar os comportamentos de acordo com aquilo que estabelecem; os constrangimentos são condicionantes dos comportamentos e, por isso, não se aplicam nem se lhes obedece, impõem-se por força
A estes princípios dou o nome de constrangimentos ou, para utilizar a terminologia mais frequente no Brasil, vínculos, no sentido que a Escola de Palo Alto dava à expressão bind (Watzlawick, Beavin \& Jackson, 1993).

Na constituição da esfera pública, as pessoas estão constantemente confrontadas com exigências que as obrigam a escolher entre opções contraditórias. É o caso, por exemplo, das escolhas que têm de fazer entre o respeito da igualdade e o reconhecimento das diferenças, quando estão em jogo questões que se prendem com as decisões acerca do direito da igualdade versus diferença de género, de orientação sexual, de repartição dos recursos, da expressão pública de símbolos particulares da identidade cultural e/ou religiosa de comunidades minoritárias, numa palavra acerca das questões fraturantes, para as quais não é possível encontrar soluções consensuais.

De todas as questões fraturantes as que mais dificuldades levantam para a constituição de consensos são

das circunstâncias e o mais que se pode fazer é procurar contorná-los. as que têm a ver com a delimitação das fronteiras definidoras de situações limite, tais como as da delimitação das fronteiras da vida, da morte, do universo. Como constituir um público dos que aceitam a legitimidade do aborto antes de determinada data de gestação, da eutanásia, de uma fronteira da morte ou de uma fronteira delimitadora do universo? Afinal, se observarmos com atenção cada uma das questões em torno das quais um público pode ser constituído, descobrimos que todas têm a sustentar as suas posições a impossibilidade de delimitação da fronteira das realidades que dizem respeito a essas questões. É essa impossibilidade que está na origem dos constrangimentos a que estão sujeitas as relações intersubjetivas responsáveis pelo processo de institucionalização das diferentes dimensões da vida coletiva. Por onde passa a linha delimitadora, por exemplo, da diferença sexual, da identidade cultural, da identidade nacional, da crença religiosa?

Neste sentido, é particularmente interessante seguir de perto a maneira como as pessoas hoje se confrontam com estas questões e observar os 
processos que utilizam e os procedimentos que adotam, localmente, em particular nas redes sociais, onde essas questões fraturantes assumem particular relevo, para encontrarem maneiras de contornar os princípios paradoxais que constrangem os seus comportamentos e as suas decisões.

\section{Bibliografia}

Arendt, H. (2001) [1958]. A Condição Humana. Lisboa: Relógio d'Água.

Dewey, J. (1954) [1927]. The Public and its Problems. Athens, Ohio: Swallow Press/Ohio, University Press.

Durkheim, E. (1991). De la Division du Travail Social. Paris: Quadrige, PUF.

Frazer, N. (2007). Reconhecimento sem Ética?. Lua Nova, n. ${ }^{\circ} 70$. São Paulo, 101-138.

Habermas, J. (2012) [1962]. A Transformação Estrutural da Esfera Pública. Lisboa: F.C.G.

MARCOS, M.L. \& MONTEIRO, A. R. (2008). Reconhecimento. Do Desejo ao Direito. Lisboa: Colibri.

Mead, G.-H. (1992) [1934]. Mind, Self and Society. Chicago \& London: The University of Chicago Press.
Rodrigues, A. D. (2005) - A Partitura Invisível (2. ${ }^{\mathrm{a}} \mathrm{ed}$.). Lisboa: Colibri. Simondon, G. (1989). Du Mode d'Existence des Objets Techniques. Paris: Aubier.

Tarde, G. (2006) [1901]. L'Opinion et la Foule. Paris: Editions du Sandre.

Watzlawick, P., Beavin, J. H. \& Jackson, D. D. (1993) [1967]. Pragmática da Comunicação Humana. São Paulo: Cultrix. 